tual da defesa da biografia em detrimento da trajetória profissional, mas pelo que foi capaz de me fazer evocar. Lembrei-me, por exemplo, das entrevistas que fiz, entre 1992 e 1993, com os engenheiros Dr. Reis e Dr. Abelardo Coimbra Bueno e com o arquiteto Durval Lobo, que não gostava de ser chamado de doutor. O doutor Reis morava em um apartamento na rua Barata Ribeiro (ou Toneleiro, já não me lembro bem), quase esquina com Santa Clara, em Copacabana. Ele me recebeu em seu escritório, um cômodo escuro, porque, como estava quase cego, a claridade lhe era indiferente. Movimentava-se com desenvoltura em casa e continuava lendo tudo que lhe chegava à máo com um aparelho que, semelhante a uma máquina de microfilme, aumentava enormemente as letras. $\mathrm{O}$ velhinho magro, mas bastante agitado no alto dos seus 90 anos, estava separando a documentação que iria doar ao arquivo da cidade. $\mathrm{O}$ escritório era um amontoado de caixas, produto da resolução do dilema sobre o que publicizar. $\mathrm{O}$ resultado final dessa separação só soube mais tarde, quando fui ao arquivo e pude ver o que fora doado.

Das entrevistas, só me lembro de ele ter-me contado como saía correndo da Politécnica, no largo do São Francisco, para a Belas Artes, na Rio Branco, para algumas aulas, ou da personalidade de Armando de Godoy que, até então, eu desconhecia. Não pude aproveitar aqueles encontros com café e biscoito, dado o fato de o telefone interromper-nos o tempo todo; ele dizia que era o pessoal da secretaria desejando alguma informação, pois "sabia tudo da Cidade".

Nesses momentos, pude conhecer um pouco da "pessoa" do Dr. Reis, que me falou de seu encanto pela cidade do Rio de Janeiro, quando nela chegou, nos anos 1920, para estudar, e de como voltou para sua cidade natal, onde não conseguiu ficar, retornando definitivamente para a cidade que escolheu como sua. Presenciei também seu respeito e admiração pelo "chefe" Armando de Godoy (por conta disso, fez o grupo de pesquisa fazer loucuras para chegar ao neto dele), o carinho por sua companheira de toda vida e sua visão intransigente do urbanismo, relacionada à capacidade de resolver os problemas urbanos, algo próprio de uma geração de engenheiros urbanistas.
O posfácio resgatou todas essas lembranças, e talvez seja por isso que concorde com a proposição de uma biografia profissional e não de uma trajetória, como mormente preferiria, já que Dr. Reis dedicou-se não só profissionalmente mas integralmente à cidade que escolheu viver. A vida carrega o imponderável e, no caso do engenheiro biografado, podemos vê-lo nos fragmentos/rastros por ele deixados (e intencionalmente escolhidos) nos labirintos da cidade.

Em tempos em que o discurso da derrubada da Avenida Perimetral possui a mesma força (estética) de argumentação daquela utilizada para a abertura da Avenida Presidente Vargas, percorrer a trajetória de um profissional que ajudou a construir, com sua atuação, esse discurso permite-nos entender o poder de enunciação do urbanismo e seus limites: a própria cidade.

Lúcia Helena Pereira da Silva: Irentesilva@ig.com.br.

\section{A COPA DO MUNDO E AS CIDADES: POLÍTICAS, PROJETOS E RESISTÊNCIAS}

\author{
Fernanda Sánchez, \\ Glauco Bienenstein, \\ Fabrício Leal de Oliveira \\ e Pedro Novais (Org.) \\ Niterói: Editora da UFF, 2014.
}

Eduardo Alberto Cusce Nobre Universidade de São Paulo, Faculdade de Arquitetura e Urbanismo, São Paulo, SP, Brasil

Com as confirmaçóes do Brasil e do Rio de Janeiro como sedes, respectivamente, da Copa do Mundo FIFA 2014 e dos Jogos Olímpicos de 2016, uma serie de atuaçóes do poder público e da iniciativa privada em diversas esferas foi intensificada, a fim de garantir a realização desses dois megaeventos esportivos. Os interesses bilionários que os patrocinam fizeram com que determinadas intervençôes 
resultassem em fortes impactos físico-espaciais e socioeconômicos sobre as cidades e seus moradores. É justamente nesse contexto que as análises presentes no livro A Copa do Mundo e as cidades: politicas, projetos e resistências (2014), organizado por Fernanda Sánchez, Glauco Bienenstein, Fabrício Leal de Oliveira e Pedro Novais, inserem-se.

Com um time invejável de autores, pesquisadores brasileiros e estrangeiros de formação acadêmica diversificada, a obra busca compreender, em diferentes escalas, os resultados da realização desses megaeventos, sendo dividida em quatro partes: "Projetos Políticos e Projetos de Intervenção Urbana"; "Cidades da Exceção para a Copa de 2014"; "Rupturas no Maracanã: arquitetura, patrimônio e espaço público"; e, por fim, "Impactos e Resistências".

A primeira parte desenvolve-se em quatro artigos, com diferentes abordagens sobre projetos políticos e de intervenção urbana voltados a megaeventos esportivos. O primeiro deles, $A$ construção da imagem urbana orientada por grandes eventos: potemkinismo, a midia e a periferia, da pesquisadora Anne-Marie Broudehoux, examina a construção da imagem urbana e do city marketing e seus impactos no direito à cidade. Para tanto, a autora faz uso do conceito de potemkinismo - projeção de uma visão idealizada de cidade, que tanto embeleza como falsifica a realidade. A utilização dessa prática revela a relação desigual de poder entre o sujeito avaliado e seu avaliador e se adequa, perfeitamente, às práticas realizadas por países emergentes quando sediam megaeventos esportivos. Nesses casos, o potemkinismo não é usado somente para mascarar as relaçôes de poder do país anfitriāo e o mundo, mas também é utilizado pelas coalizões políticas internas. No intuito de melhorar sua imagem para o mundo e para a populaçáo local ou, dito de outro modo, de superar a sua situação precária no ranking simbólico das naçôes e adquirir respeito global, ocultam-se as realidades socioeconômicas e a condição pós-colonial desses países. Ainda sobre os megaeventos, a autora chama a atenção para o importante aspecto da criação da imagem e da midiatização, visto que os Jogos Olímpicos e a Copa do Mundo disputam o título de "evento mais assistido do planeta". Nesse sentido, as federações organizadoras desses eventos e seus patrocinadores passam a ter influência no gerenciamento urbano da cidade anfitriā. Segundo Broudehoux, isso resulta em mais uma forma de injustiça urbana, na qual o pobre, o feio e o informal são excluídos, mesmo que imageticamente, da realidade urbana por meio de uma imagem pouco problematizada, despolitizada e simplificada. Essa tática vem ao encontro dos anseios da elite local, que deseja uma cidade livre dos pobres, além de poder ser usada como justificativa a favor de políticas urbanas excludentes, de modo a marginalizar as açóes e deslegitimar as reivindicaçóes dos movimentos sociais.

Em A construção dos BRICs por meio da construção de estádios: reflexóes preliminares sobre os recentes e futuros megaeventos esportivos em quatro economias emergentes, John Horne analisa as tensões subjacentes à realização de megaeventos fora dos centros urbanos do hemisfério norte e o papel da mídia na construção da cultura de consumo nesses eventos, fundamentado nas seguintes perguntas: Quem de fato se beneficia dos megaeventos esportivos? Quem são os excluídos? O ativismo social dentro dos megaeventos esportivos pode desafiar as relaçóes consolidadas de poder, provocando mudanças progressistas no esporte?

$\mathrm{O}$ autor procura estabelecer uma agenda da pesquisa sobre a realização dos megaeventos em economias em desenvolvimento, especificamente nos chamados BRICs (Brasil, Rússia, Índia, China). Como ele mostra, o alto custo para a efetivação deles no contexto dos países supracitados pode pôr o processo de produção em xeque; em contrapartida, essa dificuldade faz com que o evento tenha um maior peso político e simbólico para os governantes. Horne levanta, diante disso, quatro problemas principais a serem estudados: São os megaeventos esportivos táo populares como se imagina? As instalações esportivas construídas serão utilizadas posteriormente? Quem está sendo submetido à vigilância crescente com as novas tecnologias de segurança desses eventos? Qual a imagem que de fato os países emergentes estáo passando ao sediar um megaevento esportivo? E, finalmente, questiona: qual será então o legado dos megaeventos esportivos nos BRICs?

No artigo Copa do Mundo, megaeventos e projeto de cidade: atores, escalas de açáo e conflitos no Rio de 
Janeiro, Fernanda Sánchez aborda o caso do Rio de Janeiro e da "política-espetáculo" para megaeventos esportivos, inserida no cenário das políticas urbanas neoliberais. Compreendendo os megaeventos como uma forma contemporânea de conceber o planejamento urbano e as intervençóes nas cidades, a pesquisadora afirma que a revisitação de estudos de caso acerca do "legado" demonstra que os benefícios sociais e materiais são decepcionantes e que a retórica dos efeitos positivos desses eventos não se sustenta. Tais aspectos negativos acentuam-se em países extremamente desiguais como o Brasil, onde a realização dos megaeventos tende a enfatizar a desigualdade. Para confirmar seu argumento, são analisados os Jogos Panamericanos de 2007, os preparativos para a Copa do Mundo 2014 e dos Jogos Olímpicos 2016. Conforme ela demonstra, para a realização desses eventos, o poder público concentra investimentos nas áreas de interesse do capital imobiliário no interior dos bairros nobres da cidade. A população mais pobre é removida e não há redistribuição dos benefícios de infraestrutura urbana para o resto da cidade. Pior ainda, investimentos públicos são realizados na construção de equipamentos que, no futuro, serão comercializados pela iniciativa privada dentro de uma lógica mercadológica, favorecendo a especulação imobiliária, as empreiteiras e o setor hoteleiro. A cidade se transforma numa "cidade de exceção", apoiada nas parecerias público privadas, nos grandes projetos urbanos e na flexibilização da lei. Contudo, ao lado dos efeitos negativos dos eventos analisados, Fernanda mostra como a sociedade civil não se manteve passiva ao processo, pois grandes manifestaçóes, com eventual apoio do judiciário, conseguiram algumas vitórias, como a permanência da Comunidade Vila Autódromo e a revisão da reforma do Complexo do Maracanã e arredores.

No texto 2014 e o desenhar conflituoso de uma nova geografia do futebol, Gilmar Mascarenhas desenvolve um trabalho no campo da geografia do futebol, retomando a sua história. Jogado, anteriormente, em locais improvisados e assistidos pelos parentes dos jogadores, o futebol transformou-se. A expansão lucrativa da "indústria do espetáculo" proporcionou a popularização dos "clubes", o que arregimentou uma legiáo de fấs do novo modelo do esporte. Esses dois circuitos geraram, como o autor demonstra, uma geografia específica do futebol: enquanto no primeiro caso ele é praticado, informalmente, de acordo com os interesses dos praticantes voluntários, em quadras escolares e/ ou campos improvisados nas praças, ruas, praias e parques, representando uma poderosa máquina de socialização, no segundo, depende da ação do poder público ou da iniciativa privada para a construção de um local específico para os jogos, o estádio. É dessa segunda geografia que o trabalho do autor trata, considerando os impactos que a Copa do Mundo 2014 pode trazer ao equipamento estádio e para sua apropriaçáo social, dado que opera como fomentador de sentido de pertencimento e como construtor de identidades coletivas.

Analisando a evolução dos estádios no Brasil como grandes equipamentos populares, Mascarenhas aponta para um ponto de inflexão nos anos de 1980, quando a nova economia do futebol, baseada em contratos milionários de transmissão televisiva e de seus patrocinadores, leva à falência o grande estádio popular, produzindo, assim, uma "nova cultura do futebol". Consonante a argumentação do autor, a Copa do Mundo pode resultar no recrudescimento desse processo com a remodelação arquitetônica elitista dos estádios, na qual se entrevê uma nova configuração de público, caracterizado pela expansão feminina, de idosos e crianças, e, em função do aumento do custo dos ingressos, pelo "branqueamento" forçado produzido pela exclusão das camadas economicamente desfavorecidas.

A segunda parte do livro examina a produção da cidade de exceção a partir dos preparativos para megaeventos esportivos, tomando como exemplo as cidades do Rio de Janeiro e Curitiba.

O artigo Megaeventos no Brasil e no Rio de Janeiro: uma articulação transescalar na produção da cidade de exceção, de Nelma Gusmão de Oliveira e Carlos Vainer, em uma análise transescalar, examina o papel das federaçôes esportivas Fédération Internationale de Football Association (FIFA) e Comitê Olímpico Internacional (COI) na promoção dos megaeventos e seus impactos na cidade do Rio de Janeiro, trazendo à baila as diversas relaçóes de poder estabelecidas. O texto analisa a conversão dessas entidades em empresas bilionárias a partir da 
década de 1970, quando os eventos que elas promoviam transformaram-se em um meganegócio de marketing. $\mathrm{O}$ patrocínio de empresas transnacionais de variados ramos, marcas esportivas, alimentação, automotivo, bebidas, eletroeletrônicos, telecomunicaçóes, etc., associado à venda dos direitos de transmissão televisiva e comercialização dos direitos comerciais de eventos esportivos, fez com que essas federaçôes adquirem-se a forma de empresas transnacionais, com poder de decisão supranacional, sendo-lhes possível, por exemplo, ditar regras sobre a construção e localização de estádios e alterar legislaçóes nacionais e locais. Os países e cidades-sede tornam-se, entâo, reféns dessas entidades, sob o risco de perderem o evento se não aceitarem as suas regras. Analisando o caso brasileiro, os autores citam a aprovação das leis de exceção, como: o Regime Diferenciado de Contratação (RDC); a Lei Geral da Copa; a concessão administrativa do Complexo do Maracaná; o Plano de Estruturação das Vargens da Barra de Tijuca e a Operação Urbana Consorciada do Projeto Porto Maravilha, que flexibilizaram parâmetros urbanísticos; o decreto municipal que restringe o comércio ambulante, a liberdade de manifestação e põe à disposição dos Jogos Olímpicos imóveis públicos - além de todas as medidas de segurança e higienização social, como desapropriação e remoção de comunidades de baixa renda e ocupação militar dos morros.

Copa do Mundo 2014 em Curitiba: o jogo da exceção, de Frédi Vasconcelos, José Ricardo Vargas de Faria e Simone Aparecida Polli, também aborda a adoção do paradigma do "Estado de exceção" no modelo aplicado às cidades-sede da copa, tomando como exemplo a cidade de Curitiba, que construiu uma imagem de cidade-modelo desde os anos de 1960 e que, a partir dos anos de 1990, viu o planejamento urbano de concepção modernista dar lugar ao planejamento estratégico. A sua escolha como uma das 12 cidades-sede da Copa do Mundo 2014 favoreceu esse processo. Nele, foram necessários recursos públicos, disponibilizados, via empréstimo, pelo Banco Nacional de Desenvolvimento Econômico e Social (BNDES), para realizar a reforma do Estádio Arena da Baixada, de propriedade privada do Clube Atlético Paranaense. Para viabilizar o empréstimo, o governo do Estado e a prefeitura precisaram intervir, utilizando recursos da arrecadação da transferência de potencial construtivo, de utilização exclusiva em obras de interesse público, como contrapartida exigida pelo banco. As obras de mobilidade aprovadas na matriz de responsabilidade tiveram um grande aumento em relação ao que fora orçado inicialmente, já que os projetos foram aprovados sem detalhamento. A urgência para conseguir recursos federais para o financiamento desses projetos fez com que órgãos públicos renomados, como o Instituto de Pesquisa e Planejamento Urbano de Curitiba (IPPUC) e a Caixa Econômica Federal (CEF), deixassem de lado o rigor e as exigências de praxe a fim de agilizar o processo. Segundo os autores, os prejuízos com as mudanças dos projetos recairão, futuramente, sobre a Prefeitura Municipal de Curitiba.

Cristina Lontra Nacif e Lucas Faulhaber, no texto Desapropriaçóes e Remoçóes para tornar $o$ Rio de Janeiro 'competitivo', mostram como as obras voltadas ao processo de reestruturação do Rio de Janeiro para os eventos da Copa do Mundo FIFA e dos Jogos Olímpicos sustentaram a vertiginosa valorização imobiliária da cidade nos últimos anos. Inseridas dentro da lógica das cidades competitivas, promovida pelas cartilhas das agências multilaterais, essas obras são baseadas na flexibilização da legislação urbanística e nas reformas das estruturas institucionais com vistas a criar uma gestão livre das "amarras" do Estado. Para atingir esses objetivos, a administração municipal submete parcela significativa da população a processos violentos de deslocamentos compulsórios, resultantes das desapropriaçóes destinadas às obras de infraestrutura e aos equipamentos esportivos para megaeventos. No mapeamento dos decretos expropriatórios do governo, percebe-se a sua concentração na área portuária, consequência do projeto Porto Maravilha, e ao longo dos corredores viários que apoiam os "clusters" olímpicos, principalmente nas áreas mais valorizadas da cidade ou com potencial de valorização após as obras. Em tais casos, a maioria da população removida preferiu optar pela mudança para condomínios financiados pelo Programa Minha Casa Minha Vida (PMCMV), que, apesar de possuírem melhor qualidade construtiva, localizam-se em 
regióes periféricas, distantes das oportunidades de trabalho e com imenso deficit em infraestrutura e equipamentos sociais. Dessa forma, as obras realizadas para os megaeventos esportivos representaram a relocação da população pobre na periferia, em condiçóes mais precárias, ocasionando uma valorização ainda maior de regiốes já valorizadas.

$\mathrm{Na}$ terceira parte, "Rupturas no Maracanã: arquitetura, patrimônio e espaço público”, dois textos discutem as transformaçôes físicas e simbólicas pelas quais o Estádio Jornalista Mário Filho, o Maracanã, teve de passar para adaptar-se às normas da FIFA e do COI para sediar os megaeventos.

Gustavo Prieto e Juliana Nazaré Luquez Viana, em No templo do futebol, a privatização da vida cotidiana: da festa para a elitização na cidade espetáculo, optam por uma abordagem mais geográfica e antropológica. A partir do preceito de que o futebol é um complexo fenômeno socioespacial da vida cotidiana nas metrópoles brasileiras contemporâneas, o texto intenta entender a relação do futebol com a metrópole do Rio de Janeiro, tendo como objeto analítico o estádio do Maracanã e a importância dele para seus frequentadores. Considerando-o como espaço público de lazer e entretenimento na cidade, analisa sua inserção na atual lógica da privatização, marcada pela abertura de novos nichos de mercado para a reprodução do capital, frente à apropriação simbólica dos torcedores. $\mathrm{O}$ jogo de futebol e o estádio conferem ao esporte uma atmosfera de sacralidade e de comunhão. Contudo, como demonstram os autores, a elitização e mercantilização da festa póem em risco tal sacralização. $\mathrm{O}$ aumento significativo do preço dos ingressos e o patrocínio das grandes corporaçóes transnacionais levaram ao aumento da renda nos jogos, mas, na contramáo desse resultado, houve queda de público. Observa-se, com isso, que a lógica de reprodução do capital domina e subverte o espetáculo, transformando-o em mercadoria-futebol: o torcedor é submetido à lógica do consumidor, com sua participação e manifestações normatizadas, fato que elimina a sacralidade e comunhão do espetáculo.

Glauco Bienenstein, Leonardo Mesentier, Bruno Guterman e Vítor Hugo Teixeira, em $A$ batalha pela preservação da alma do Maracanã: disputas simbólicas, lutas sociais, cidade e arquite- tura, averiguam os desdobramentos físicos, arquitetônicos, simbólicos e socioespaciais das obras desenvolvidas no Maracanã para a Copa do Mundo FIFA 2014 e as Olimpíadas 2016. Ressaltando a sua centralidade física e simbólica, o trabalho aborda as diversas reformas operadas desde os anos 1990 para adaptar o estádio às normas cada vez mais restritivas da FIFA, que tendem a diminuir o apelo popular do equipamento. Sob a desculpa dos preceitos técnicos, sua capacidade vem sendo reduzida paulatinamente e o estádio original sofreu grande descaracterização, apesar de ser tombado pelo Instituto do Patrimônio Histórico e Artístico Nacional (IPHAN). Os pesquisadores sugerem que essas sucessivas alteraçóes implicaram mudanças no comportamento e na composição social dos torcedores, além de diminuir a arquitetura do estádio como suporte da memória coletiva. As mudanças recentes não ocorreram sem irrupçóes de resistência contra o projeto elitista e privatista de adequação do estádio ao padrão de consumo globalizado. $\mathrm{O}$ artigo ressalta, por exemplo, o papel do Comitê Popular da Copa e das Olimpíadas como principal articulador desses movimentos contra a privatização e elitização do estádio.

A última parte, "Impactos e Resistências", traz um texto de Giselle Tanaka e Roberto Cosentino, intitulado Comitê Popular da Copa e Olimpiadas do Rio de Janeiro: movimentos sociais e novas articulaçóes. Nele, aborda-se a atuação do Comitê Popular, organização de grupos da sociedade civil que denuncia as violaçôes de direitos humanos e os impactos das decisões arbitrárias em função de obras para megaeventos. Apesar de sua atuação, seu alcance tem sido limitado, dado o contexto de exceção para blindar os megaeventos da participação pública e democrática. Diante disso, os comitês têm apoiado a realização de planos populares e projetos alternativos para mostrar que a sociedade tem propostas. O Comitê do Rio de Janeiro adotou, por exemplo, duas campanhas com relaçấo aos megaeventos esportivos: a "Rio sem remoções”, opondo-se à remoção arbitrária da população excluída em função das obras dos megaeventos; e a "O Maraca é nosso", contra o plano de privatização e remodelação comercial do estádio do Maracanã. As manifestaçóes de junho 
de 2013, que levaram às ruas mais de um milhão de pessoas, contrapondo-se ao aumento das tarifas do transporte público, acabaram também por questionar a validade da realização da Copa do Mundo FIFA 2014 e os gastos públicos nesse processo. Com isso, houve recuo do Estado nas principais obras de remodelação do complexo do Maracanã e a prefeitura reviu a sua pauta de remoçôes, o que conferiu aos movimentos sociais uma vitória parcial.
As diferentes abordagens presentes no livro conferem ao leitor, portanto, uma visão crítica, abrangente e aprofundada dos impactos sofridos pelas cidades brasileiras e pela população, em especial no caso Rio de Janeiro, com os preparativos para sediar megaeventos esportivos, compreendidos, aqui, como uma estratégia de acumulação e reprodução do capitalismo contemporâneo globalizado.

Eduardo Alberto Cusce Nobre: eacnobre@usp.br. 